\title{
Trace Metals in the Bed Sediment of Small Urban Streams
}

\author{
Jana Nabelkova* and Dana Kominkova
}

\begin{abstract}
CTU in Prague, Faculty of Civil Engineering, Department of Sanitary and Ecological Engineering, Thakurova 7, 16627 Prague 6, Czech Republic
\end{abstract}

\begin{abstract}
Trace metals (TMs) are still a serious problem in urban streams because of their toxicity and continuing significant levels in the aquatic environment, especially in bed sediments. Concentrations of $\mathrm{Cd}, \mathrm{Cr}, \mathrm{Cu}, \mathrm{Ni}, \mathrm{Pb}$ and $\mathrm{Zn}$ were monitored in the sediments of several small streams in the Prague area. These streams differ in the main source of pollution (combined sewer overflow - CSO, storm water drain - SWD, or waste water treatment plant - WWTP). The potential TMs hazard was assessed by several indexes, and the dependence of TMs concentrations on various sediment material characteristics was evaluated. The bioavailability of TMs was also assessed by comparing the binding strength of metals in the sediment and their concentrations in aquatic organisms in these creeks. Of the metals studied, Cd is the most available from sediments, but the other metals were also easily released from the sediment to the liquid phase. There were also differences in TMs bioavailability from sediments of creeks with different main pollution source, and was higher in creeks impacted by WWTP and SWD.
\end{abstract}

Keywords: Bed sediment, sequential extraction, small urban stream, trace metals, urban drainage, hazard assessment.

\section{INTRODUCTION}

Watercourses in urban areas are strongly affected by different anthropogenic activities, with urban drainage playing the most important role. Waste water and storm water modify the quality of the aquatic environment in chemical, morphological as well as biological parameters. Combined sewer overflows (CSOs) and Storm water drains (SWDs) are sources of pollution particularly under wet-weather conditions. Loading of contaminants from CSOs depends on proportions and quality of municipal, commercial as well as industrial wastewaters. In some cases SWDs can be even more significant sources of contaminants. According to Chambers et al. [1] urban runoff significantly exceeds those associated with municipal wastewater. Marsalek et al. [2] for instance reported that in the Canadian Great Lakes region urban runoff discharges annually $10^{5}$ tonnes of suspended solids, $10^{4}$ tonnes of chloride and $10^{2}$ to $10^{3}$ tonnes of trace metals.

Though loading of contaminants to receiving waters from stormwater discharges is episodic and causes a short-term pulse of exposure, sediments in receiving waters frequently accumulate them. Pollutants associated with sediments may become temporarily bioavailable to the organisms in nondepositional areas because of dispersion caused by a hydraulic action [3].

Numerous studies have assessed an exposition of biological communities in receiving waters to wet-weather runoff. Most of these studies are focused on benthic invertebrate

*Address correspondence to this author at the CTU in Prague, Faculty of Civil Engineering, Thakurova 7, 166 29, Prague 6, Czech Republic;

Tel: +420 224354 350; Fax: +420 224355 474;

E-mail: nabelkova@fsv.cvut.cz communities. These organisms may have a greater degree of contact with pollutants derived from stormwater discharges than others. They are highly relevant in environmental studies because of their sedentary nature, ubiquity, responsiveness to disturbances, easy of sampling and importance for other ecosystem components. The studies usually confirm toxicity of sediments, porewater and overlying water in stormwater-exposed aquatic systems $[4,5]$. On the other hand, there are also studies reporting, that biological degradation occurs as a result of habitat changes, and that there is limited evidence for contaminant-induced impairment $[6,7]$.

Trace metals (TMs) belong to the group of specific pollutants associated with urban drainage (industrial waste water as well as stormwater runoff from traffic areas). They are very significant because of their toxicity for organisms, ability to bioaccumulate and biomagnification in the food chain.

The mobility of TMs in aquatic ecosystems and their toxicological impact on organisms have not been very well understood yet, especially in the environment where frequent and fast changes of conditions occur. This type of the environment is typical particularly for small urban streams, where urban drainage significantly changes the flow as well as physical and chemical conditions of water $(\mathrm{pH}$, conductivity, hardness, redox potential, etc.). These changes can lead to the remobilization of TMs from sediments back to the water and consequently to the increase of bioavailability. TMs tend to be bound in the solid phase of the aquatic environment - suspended solids and bed sediment [8-13]. This means that except for during acute events (e.g. storms, accidental releases, flooding), their concentrations in the water (liquid phase) should be less significant. However, sediments serve as a storage site where TMs can accumulate to very high levels for long periods. The concentrations in 
Table 1. Basic Hydrological Data of the Studied Creeks

\begin{tabular}{|c|c|c|c|c|}
\hline & \multirow{2}{*}{ Impact } & Length & Catchment Area & Average Flow \\
\hline & & km & $\mathbf{k m}^{2}$ & $\mathbf{m}^{3} \cdot \mathrm{s}^{-1}$ \\
\hline the Botic creek (B) & $\mathrm{CSO}$ & 34.5 & 134.9 & $0.3-0.4$ \\
\hline the Rokytka creek (R) & $\mathrm{CSO}$ & 36.2 & 134.9 & $0.3-0.4$ \\
\hline the Zatissky creek (Z) & SWD & 3.1 & 5.0 & $0.02-0.03$ \\
\hline the Kunraticky creek (K) & SWD & 14.8 & 31.6 & $0.05-0.06$ \\
\hline the Uneticky creek (U) & WWTP & 13.4 & 47.6 & $0.09-0.10$ \\
\hline the Vinorsky creek (V) & WWTP & 12.9 & 40.5 & $0.03-0.04$ \\
\hline
\end{tabular}

sediments directly affect benthic invertebrate organisms and are also potentially dangerous for other aquatic and terrestrial organisms, either because of their transfer in the food chain or during acute situations when pollutants from sediment can be remobilized to the liquid phase and be directly uptaken by organisms.

The aim of this paper is to analyze the potential hazard that TMs concentrations in bed sediments can cause for aquatic life in the different conditions of small urban streams affected by different types of urban drainage.

\section{METHODS}

\section{Description of the Studied Creeks}

We studied six small urban streams in the Prague area affected by different types of urban drainage and therefore differing in their main source of pollution. The first two creeks, the Botic creek (B) and the Rokytka creek (R), are both significantly affected by combined sewer overflows (CSO). However, they differ in channel characteristics as well as the quality of waste water affecting them. Whereas CSO in the Botic creek loads the stream by pollution originating from industrial waste water and runoff from heavy traffic areas, CSO in the Rokytka creek mainly originates from domestic waste water. Moreover, the sediment of the Rokytka creek in the studied section is affected by sediment washing out from the Kyjsky pond, which is loaded by industrial-origin TMs contamination. The second group of studied creeks, the Zatissky creek $(Z)$ and the Kunraticky creek $(\mathrm{K})$, are characterized by storm water drain (SWD) impacts. The sediment in these creeks, especially in the Zatissky creek, is often flushed away during rain events because of extreme flow rates caused by the high percentage of impermeable surfaces in the catchments. The third group of streams, impacted by WWTP, is comprised of the Uneticky creek, impacted by WWTP from the Prague airport, and the Vinorsky creek, that is loaded by strong industrial contamination from historical activities. Basic hydrological data of all studied creeks is shown in Table $\mathbf{1}$.

\section{Methods - Analyses}

Concentrations of the toxic metals $\mathrm{Cd}, \mathrm{Cr}, \mathrm{Cu}, \mathrm{Ni}, \mathrm{Pb}$ and $\mathrm{Zn}$ in water and sediments of the studied creeks were regularly monitored (five times a year: for three years in the Botic, Rokytka and Zatissky creeks and for one year in the Kunraticky, Vinorsky and Uneticky creeks). Water samples were fixed by the addition of a small amount of $\mathrm{HNO}_{3}$ and analyzed by an atomic absorption spectrometer with graphite furnace atomization (GFAAS). Sediment samples were frozen, freeze-dried, sieved to separate larger components $(>600 \mu \mathrm{m})$ and microwave digested in $\mathrm{HNO}_{3}$ and $\mathrm{H}_{2} \mathrm{O}_{2}$ (method USEPA 3051, 1994) before analysis on an atomic absorption spectrometer with flame or graphite furnace atomization (FAAS or GFAAS).

Selected sediment samples were sieved to separate according to grain size distribution (fractions 200-600 $\mu \mathrm{m}, 63-$ $200 \mu \mathrm{m},<63 \mu \mathrm{m}$ ), and to analyze the binding behavior of TMs in sediments of different characteristics. The amount of organic matter in these sediment samples was analyzed as loss on ignition. These sediment samples were digested by the sequential extraction procedure of Tessier et al. [14] slightly modified by Nabelkova [9] to study the binding strength of the most problematic TMs in the studied creeks $(\mathrm{Cd}, \mathrm{Cu}, \mathrm{Pb}$ and $\mathrm{Zn})$, as identified by a hazard assessment (described below). Though a new procedure of sequential extraction BCR is implemented in European countries [15], the Tessier's protocol is still widely used all over the world [16-19], because it distinguishes five different geochemical fractions (BCR only four) and allows comparison with older data. Based on this sequential extraction procedure, concentrations of TMs in the following geochemical fractions were analyzed: exchangeable, carbonates, Fe/Mn oxides, organic matter and the residual.

Concentrations of TMs were also monitored in aquatic organisms, mainly in benthic invertebrates. After a biological survey, organisms were transported to the laboratory, identified, separated by species and size, then freeze and freeze-dried. Prior to analyses, organisms were microwave digested in $\mathrm{HNO}_{3}$ and $\mathrm{H}_{2} \mathrm{O}_{2}$ [20].

\section{Methods - Hazard Assessment}

Concentrations of TMs in water were compared with the Environmental Quality Standard (EQS) of Government Order 229/2007 [21]. An estimation of bioavailability and the hazard of metals in sediments was based on several indexes:

Distribution Coefficient $\left(K_{d}\right)$ is the ratio between a pollutant concentration in sediment $\left(\mathrm{c}_{\mathrm{s}}\right)$ and its concentration in water $\left(\mathrm{c}_{\mathrm{w}}\right)$ :

$$
K_{d}=\frac{C_{s}}{C_{w}}\left[L . \mathrm{kg}^{-1}\right]
$$


Table 2. Quantifying the Risk of Contaminated Sediment for the Water Environment by RAC.

\begin{tabular}{|c|c|c|c|c|c|}
\hline RAC & $\mathbf{1}$ & $\mathbf{2}$ & $\mathbf{3}$ & $\mathbf{4}$ & $\mathbf{5}$ \\
\hline MF & $<1 \%$ & $1-10 \%$ & $11-30 \%$ & $31-50 \%$ & $>50 \%$ \\
\hline Risk & no & low & intermediate & high & very high \\
\hline
\end{tabular}

Table 3. Average Concentrations of tms in Sediments (mg.kg-1) of Studied Creeks

\begin{tabular}{|c|c|c|c|c|c|c|c|}
\hline & & $\mathbf{C d}$ & $\mathbf{C u}$ & $\mathbf{C r}$ & $\mathbf{N i}$ & $\mathbf{P b}$ & $\mathbf{Z n}$ \\
\hline \hline \multirow{3}{*}{ CSO impact } & $\mathrm{B}$ & $0.31 \pm 0.05$ & $105.0 \pm 11.0$ & $44.5 \pm 3.2$ & $16.4 \pm 1.3$ & $51.6 \pm 10.4$ & $187.0 \pm 32.1$ \\
\cline { 2 - 8 } & $\mathrm{R}$ & $0.82 \pm 0.11$ & $50.1 \pm 3.5$ & $27.8 \pm 1.6$ & $19.5 \pm 2.5$ & $44.9 \pm 8.3$ & $214.3 \pm 15.6$ \\
\hline \multirow{3}{*}{ SWD impact } & $\mathrm{K}$ & $0.90 \pm 0.09$ & $24.0 \pm 2.2$ & $16.0 \pm 0.9$ & $20.4 \pm 1.4$ & $14.0 \pm 2.1$ & $102.0 \pm 15.4$ \\
\cline { 2 - 8 } & $\mathrm{Z}$ & $0.17 \pm 0.03$ & $9.7 \pm 0.9$ & $17.23 \pm 3.2$ & $14.2 \pm 2.5$ & $15.0 \pm 1.3$ & $47.8 \pm 9.5$ \\
\hline \multirow{2}{*}{ WWTP impact } & $\mathrm{V}$ & $5.8 \pm 1.0$ & $11.9 \pm 1.7$ & $15.1 \pm 1.5$ & $8.0 \pm 1.2$ & $7.5 \pm 0.4$ & $64.3 \pm 10.3$ \\
\cline { 2 - 8 } & $\mathrm{U}$ & $0.37 \pm 0.06$ & $37.8 \pm 4.1$ & $23.4 \pm 1.6$ & $18.5 \pm 0.9$ & $27.3 \pm 5.1$ & $203.5 \pm 20.1$ \\
\hline
\end{tabular}

$\mathrm{K}_{\mathrm{d}}$ gives information about what medium (water or solid phase) is crucial for the risk assessment [22]. This distribution coefficient is one of the most important parameters for assessing the migration potential of a contaminant present in the liquid phase that is in contact with sediment or suspended matter. Values of $\log K_{d}>5$ are calculated for elements/compounds that prefer binding to solid phases and only marginally migrate into liquid phase. On the contrary, values of $\log \mathrm{K}_{\mathrm{d}}<4$ characterize chemicals more easily released from solid phases and $\log K_{d}<3$ chemicals present preferentially in the liquid phase [10].

Hazard Quotient (HQ) characterizes the danger of a pollutant for the aquatic environment by comparison with a particular EQS. To evaluate the pollutant concentration in sediment, the following equation can be used:

$$
H Q=\frac{C_{s}}{E Q S}
$$

where $c_{s}$ is the measured concentration of a pollutant in sediment and EQS is a suitable criterion for the assessment of sediment quality. In this study, the USEPA benchmark Threshold Effect Concentration (TEC) was used because of the absence of suitable criteria in Czech national legislation. An ecological hazard is indicated for $\mathrm{HQ}>1$ [23]. Based on the value of HQ, it is possible to predict changes in benthic community composition by categorization according to Clements et al. [24]: $\mathrm{HQ}<1$ indicates unpolluted locality with no or reversible effect on aquatic organisms; $1<\mathrm{HQ}<2$ shows low pollutant load with no acute danger for organisms; $2<\mathrm{HQ}<10$ signalizes intermediate pollutant load with fatal effect to sensitive species and HQ $>10$ means high pollutant load reflecting on benthic diversity decrease.

Mobility Factor (MF). The bioavailability and consequently the hazard of problematic metals $(\mathrm{Cd}, \mathrm{Cu}, \mathrm{Pb}$ and $\mathrm{Zn}$ ) according to their binding strength in sediment are evaluated by MF, as described by Kabala and Singh [25]:

$$
M F=\frac{C_{1+2}}{C_{s} \cdot 100[\%]}
$$

where $c_{1+2}$ is the concentration of a pollutant bound to the two most available geochemical sediment fractions (ex- changeable and carbonates) and $\mathrm{c}_{\mathrm{s}}$ is the overall concentration of a pollutant in sediment (the sum of concentrations in all geochemical fractions: exchangeable, carbonates, Fe/Mn oxides, organic matter and residual). This factor expresses the ability of the sediment to release mobile (the most toxic) forms of pollutants during changes of conditions in the aquatic environment.

Risk Assessment Code (RAC). Based on values of MF, the risk of sediment contaminated by $\mathrm{Cd}, \mathrm{Cu}, \mathrm{Pb}$ and $\mathrm{Zn}$ for water environment was quantified by an RAC (Table 2) [26, 27].

Biota sediment accumulation factor (BSAF). The bioavailability of TMs was verified directly by analyzing their concentrations in aquatic organisms (benthos, algae, fish). The ability of benthic organisms to accumulate metals from sediments is indicated by the BSAF, calculated as:

$B S A F=\frac{C_{B}}{C_{s}}$

where $c_{B}$ is the concentration of a metal per dry weight of an organism and $\mathrm{c}_{\mathrm{s}}$ is the concentration of that metal in sediment [28].

\section{RESULTS AND DISCUSSION}

As it was expected, water concentrations of TMs measured in all studied creeks during regular sampling were low, did not exceed EQS given by Government Order 229/2007 [21]. However, differences in the average concentrations of TMs in sediments between the studied creeks (Table 3 ) are clear. The highest concentrations of $\mathrm{Cu}, \mathrm{Cr}$ and $\mathrm{Pb}$ were seen in sediments of creeks impacted by CSO, the highest concentration of $\mathrm{Zn}$ in creeks impacted by $\mathrm{CSO}$ as well as by WWTP from the airport. Cd concentration is most significant in the sediment of the Vinorsky creek, reflecting rather past loading than recent WWTP impact.

\section{HAZARD ASSESSMENT}

The hazard assessment, performed using the indexes described above, showed interesting results. According to the distribution coefficient (Table 4 ), the metal most easily released from the sediment is $\mathrm{Cd}$; however, $\log \mathrm{K}_{\mathrm{d}}$ values $<4$ 
Table 4. Average Distribution Coefficient $(\log \mathrm{Kd})$ of Studied Creeks

\begin{tabular}{|c|c|c|c|c|c|c|c|}
\hline $\log K d$ & & $\mathbf{C d}$ & $\mathrm{Cu}$ & $\mathbf{C r}$ & $\mathbf{N i}$ & $\mathbf{P b}$ & $\mathbf{Z n}$ \\
\hline \multirow{2}{*}{ CSO impact } & $\mathrm{B}$ & 2.4 & 5.2 & 4.0 & 3.8 & 4.2 & 3.7 \\
\hline & $\mathrm{R}$ & 3.6 & 4.1 & 3.5 & 3.8 & 4.0 & 3.9 \\
\hline \multirow{2}{*}{ SWD impact } & K & 3.8 & 4.6 & 3.9 & 3.7 & 4.0 & 4.4 \\
\hline & $\mathrm{Z}$ & 3.5 & 4.2 & 3.4 & 3.3 & 3.7 & 3.6 \\
\hline \multirow{2}{*}{ WWTP impact } & $\mathrm{V}$ & 3.7 & 3.5 & 3.1 & 3.1 & 3.3 & 3.6 \\
\hline & $\mathrm{U}$ & 2.6 & 3.4 & 3.5 & 3.6 & 3.4 & 4.0 \\
\hline
\end{tabular}

Table 5. An Average Value of HQ for Metals Concentrations in Sediment and BSAF for Metals in Studied Creeks

\begin{tabular}{|c|c|c|c|c|c|c|c|c|c|c|c|c|c|}
\hline & & \multicolumn{2}{|c|}{ Cd } & \multicolumn{2}{|c|}{$\mathrm{Cu}$} & \multicolumn{2}{|c|}{$\mathrm{Cr}$} & \multicolumn{2}{|c|}{$\mathbf{N i}$} & \multicolumn{2}{|c|}{$\mathbf{P b}$} & \multicolumn{2}{|c|}{$\mathbf{Z n}$} \\
\hline & & HQ & BSAF & HQ & BSAF & HQ & BSAF & HQ & BSAF & HQ & BSAF & HQ & BSAF \\
\hline \multirow{2}{*}{ CSO impact } & B & 0.5 & 0.8 & 3.8 & 0.5 & 0.8 & 0.1 & 0.4 & 0.1 & 1.5 & 0.6 & 1.2 & 1.7 \\
\hline & $\mathrm{R}$ & 1.4 & 0.6 & 1.8 & 1.4 & 0.5 & 0.4 & 0.5 & 0.1 & 1.3 & 0.4 & 1.3 & 2.7 \\
\hline \multirow{2}{*}{ SWD impact } & K & 1.5 & 5.4 & 0.9 & 6.9 & 0.3 & 0.8 & 0.5 & 0.5 & 0.4 & 1.7 & 0.6 & 3.7 \\
\hline & Z & 0.3 & 1.5 & 0.3 & 1.7 & 0.3 & 0.2 & 0.4 & 0.6 & 0.4 & 0.3 & 0.3 & 2.0 \\
\hline \multirow{2}{*}{ WWTP impact } & $\mathrm{V}$ & 9.8 & NA & 0.4 & NA & 0.3 & NA & 0.2 & NA & 0.2 & NA & 0.4 & NA \\
\hline & U & 0.6 & 0.2 & 1.3 & 1.4 & 0.4 & NA & 0.5 & NA & 0.8 & 0.1 & 1.3 & 3.3 \\
\hline
\end{tabular}

NA - data not available (insufficient number of organisms)

Table 6. The MF and RAC Hazards of the Most Problematic TMs in Sediments

\begin{tabular}{|c|c|c|c|c|c|c|c|c|c|}
\hline & & \multicolumn{2}{|c|}{ Cd } & \multicolumn{2}{|c|}{$\mathbf{C u}$} & \multicolumn{2}{|c|}{$\mathbf{P b}$} & \multicolumn{2}{|c|}{$\mathbf{Z n}$} \\
\hline & & MF & RAC & MF & RAC & MF & RAC & MF & RAC \\
\hline \multirow{2}{*}{ CSO impact } & $\mathrm{B}$ & 16.6 & 3 & 9.3 & 2 & 2.5 & 2 & 25.6 & 3 \\
\hline & $\mathrm{R}$ & 19.7 & 3 & 3.8 & 2 & 4.5 & 2 & 42.6 & 4 \\
\hline \multirow{2}{*}{ SWD impact } & $\mathrm{K}$ & 26.4 & 3 & 8.0 & 2 & 4.0 & 2 & 33.5 & 4 \\
\hline & $\mathrm{Z}$ & 13.5 & 3 & 28.5 & 3 & 15.4 & 3 & 53.9 & 5 \\
\hline \multirow{2}{*}{ WWTP impact } & $\mathrm{V}$ & 42.6 & 4 & 17.9 & 3 & 11.6 & 3 & 38.2 & 4 \\
\hline & $\mathrm{U}$ & 25.6 & 3 & 6.1 & 2 & 3.2 & 2 & 33.7 & 4 \\
\hline
\end{tabular}

for other metals also implies relatively easy release from the sediment to liquid phase, which can happen during critical events (rain or accidental events). Differences in $\log \mathrm{K}_{\mathrm{d}}$ values among creeks for particular metals are seen as well. For instance, $\mathrm{Cu}$ and $\mathrm{Pb}$ are most available from sediments of streams impacted by WWTP. Lower $\mathrm{K}_{\mathrm{d}}$ values for $\mathrm{Zn}, \mathrm{Pb}$ and $\mathrm{Ni}$ also reflect higher availability in the Zatisssky creek, impacted by SWD.

The hazard quotient (Table 5) indicates dangerous concentrations of $\mathrm{Cu}, \mathrm{Pb}$ and $\mathrm{Zn}$ in sediments of creeks impacted by CSO. $\mathrm{Cu}$ in the Botic creek (B) can be evidence of either industrial waste water impacts or runoff from residential areas, where $\mathrm{Cu}$ materials are used for roofs components. $\mathrm{Pb}$ and $\mathrm{Zn}$ probably originate in runoff from heavy traffic areas in the catchments of both CSO impacted creeks. The value of $\mathrm{HQ}>2$ for $\mathrm{Cu}$ in the Botic creek can cause the loss of sensitive benthic species [24]. Sediments of creeks impacted by WWTP are slightly loaded by $\mathrm{Cu}$ and $\mathrm{Zn}$ (for the Uneticky creek impacted by WWTP from the airport) and according to Clements et al. [24], the HQs (ranging from 1-
2) indicate low environmental danger with no acute risks to the benthic community. The $\mathrm{Cd}$ concentration in the sediment of the Vinorsky creek is most dangerous, with an HQ value of 9.8 that can be fatal to sensitive benthic species [24]. According to HQ, sediments of creeks impacted by SWD do not seem to be significantly loaded by toxic metals (with the exception of $\mathrm{Cd}$ in the Kunraticky creek, where there is a low sediment load).

As has been commented above, $\mathrm{Cd}, \mathrm{Cu}, \mathrm{Pb}$ and $\mathrm{Zn}$ were determined to be the most dangerous of the metals studied in these creeks. Therefore, bioavailability for these metals was evaluated by the Mobility Factor and Risk Assessment Code (Table 6) based on the sequential extraction procedure ([9] and [14]) performed on selected sediment samples. An intermediate bioavailability risk (RAC 3 ) was found for $\mathrm{Cd}$ in all studied streams, except for the sediment of the Vinorsky creek where the risk was high (RAC 4). It can be assumed that a significantly higher contaminant concentration reflects a higher proportion in more bioavailable geochemical sediment fractions (exchangeable and carbonates). $\mathrm{Cu}$ and $\mathrm{Pb}$ 
Table 7. TMs Concentrations in Sediment Samples (mg.kg $\left.{ }^{-1}\right)$ Selected for Studying Binding Behavior in Sediments

\begin{tabular}{|c|c|c|c|c|c|}
\hline & & Cd & $\mathrm{Cu}$ & $\mathbf{P b}$ & $\mathbf{Z n}$ \\
\hline \multirow{2}{*}{ CSO impact } & $\mathrm{B}$ & $0.15 \pm 0.02$ & $34.4 \pm 6.2$ & $37.0 \pm 5.4$ & $53.1 \pm 11.6$ \\
\hline & $\mathrm{R}$ & $0.32 \pm 0.06$ & $40.0 \pm 3.0$ & $30.2 \pm 4.0$ & $171.3 \pm 21.3$ \\
\hline \multirow{2}{*}{ SWD impact } & $\mathrm{K}$ & $0.40 \pm 0.03$ & $19.4 \pm 3.1$ & $10.5 \pm 1.1$ & $99.3 \pm 9.9$ \\
\hline & $\mathrm{Z}$ & $0.21 \pm 0.02$ & $10.7 \pm 2.0$ & $28.8 \pm 3.8$ & $105.0 \pm 14.0$ \\
\hline \multirow{2}{*}{ WWTP impact } & $\mathrm{V}$ & $44.44 \pm 8.20$ & $209.2 \pm 21.9$ & $76.3 \pm 7.3$ & $487.6 \pm 9.4$ \\
\hline & $\mathrm{U}$ & $0.06 \pm 0.01$ & $30.0 \pm 2.0$ & $10.0 \pm 0.3$ & $67.8 \pm 8.6$ \\
\hline
\end{tabular}
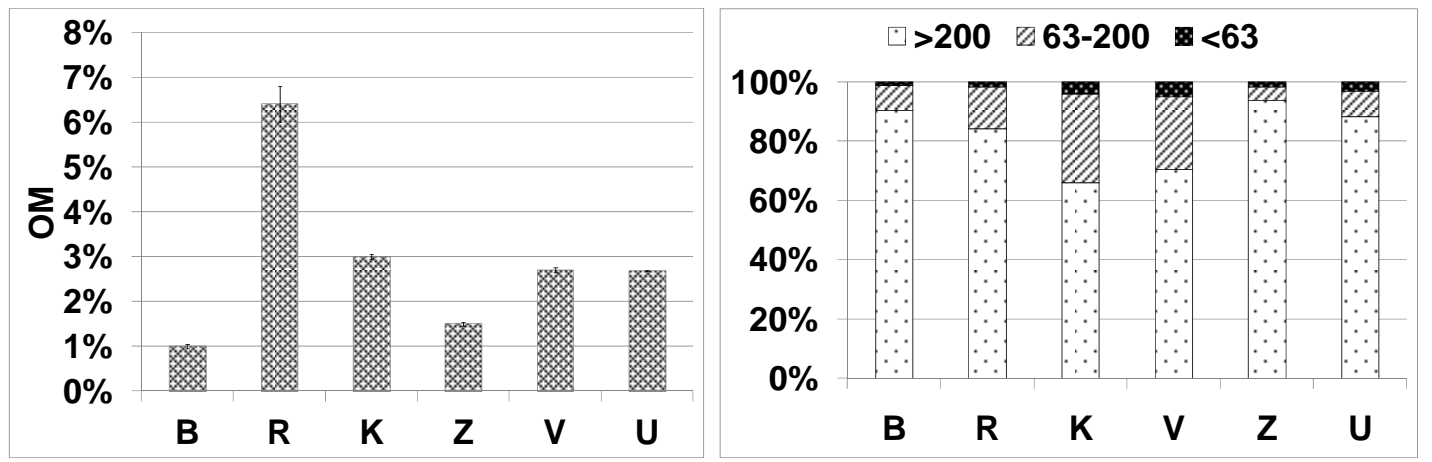

Fig. (1). The percentage of OM (left) and grain size distribution (right) in sediment samples selected for studying binding behaviour in sediments. RSD of grain size analysis up to $20 \%$.

showed intermediate risk in the Zatissky creek (impacted by SWD) and the Vinorsky creek (WWTP). According to the $\mathrm{MF}$ and $\mathrm{RAC}, \mathrm{Zn}$ is the most available and hazardous in most creeks, and is even a very high risk (RAC 5) for the Zatissky creek. The higher bioavailability of metals in the Zatissky and Vinorsky creeks is clear from Table 6. This may be caused by frequent critical events from SWD to the Zatissky creek, because during the first few minutes of rain the $\mathrm{pH}$ of water can decrease due to pollution washed out from the air of urban areas, consequently leading to the remobilization of metals from sediments [9, 29, 30]. The higher bioavailability of metals in the Vinorsky creek may be caused by high contamination (particularly in the case of Cd) rather than by the direct impact of WWTP.

Average values of the Biota Sediment Accumulation Factor (Table 5) more or less confirm the results of MF and RAC. Zn in all creeks accumulates in organisms to high levels. Organisms from creeks impacted by SWD show accumulations of TMs, especially $\mathrm{Cd}$ and $\mathrm{Cu}$, to significantly higher levels than similar species from creeks impacted by CSOs [25].

\section{BINDING BEHAVIOUR OF TMS IN SEDIMENTS OF DIFFERENT CHARACTERISTICS}

Sediment samples differing in pollutant concentrations (Table 7) as well as the amount of organic matter and grain size distribution (Fig. 1), were evaluated for the binding behaviour of the most dangerous metals $(\mathrm{Cd}, \mathrm{Cu}, \mathrm{Pb}$ and $\mathrm{Zn})$.

Based on findings of Soares et al. [8], it was assumed that the highest proportion of a pollutant is bound to the finest fraction. Fig. (2) shows concentrations of TMs in three different grain size fractions $(<63 \mu \mathrm{m}, 63-200 \mu \mathrm{m}$ and $200-$
$600 \mu \mathrm{m})$. In most creeks, these results confirm the assumption, with the exception of the Botic creek, where the highest proportion of $\mathrm{Pb}$ (and to a lesser extent $\mathrm{Cu}, \mathrm{Cd}$ and $\mathrm{Zn}$ ) is bound the intermediate grain size fraction. This could be because the Botic creek sediment had the lowest amount of $\mathrm{OM}$ (OM is usually the main component of the finest fraction) and/or it could be related to the presence of Acid Volatile Sulfides (AVS) originated in CSO that have very strong TMs binding affinity $([31,32])$ and could comprise the main part of the intermediate grain size fraction. A similar situation can be seen in the Uneticky creek for $\mathrm{Cu}$ and $\mathrm{Pb}$, though the concentration of $\mathrm{OM}$ in the Uneticky creek sediment is not as low as in Botic. Hoehn and Gunten [33] offer another explanation for this phenomenon - that metals originating from anthropogenic activities can bind to the surfaces of clay minerals that are the main part of the intermediate sediment fraction.

As shown in Fig. (3), the binding strength of toxic metals in sediment and consequently their bioavailability can also be described by the proportion of TMs concentrations in particular geochemical fractions. These results are in accordance with the calculated indexes $K_{d}, M F$ and RAC. The most available seems to be $\mathrm{Cd}$, with the highest proportion bound to the exchangeable fraction (the most available sediment fraction). On the other hand, the least available is $\mathrm{Pb}$, which is mostly bound to the residual and OM fractions (the strongest binding) except in Vinorsky creek. The difference in the Vinorsky creek may be explained by high $\mathrm{Cd}$ and $\mathrm{Zn}$ contamination in the analyzed sample, which may occupy binding positions for other metals. It is possible to generalize the availability of TMs in the studied creeks in the order: $\mathrm{Cd}>\mathrm{Zn}>\mathrm{Cu}>\mathrm{Pb}$. Comparing the studied streams (and different impacts), there are evident differences among different 

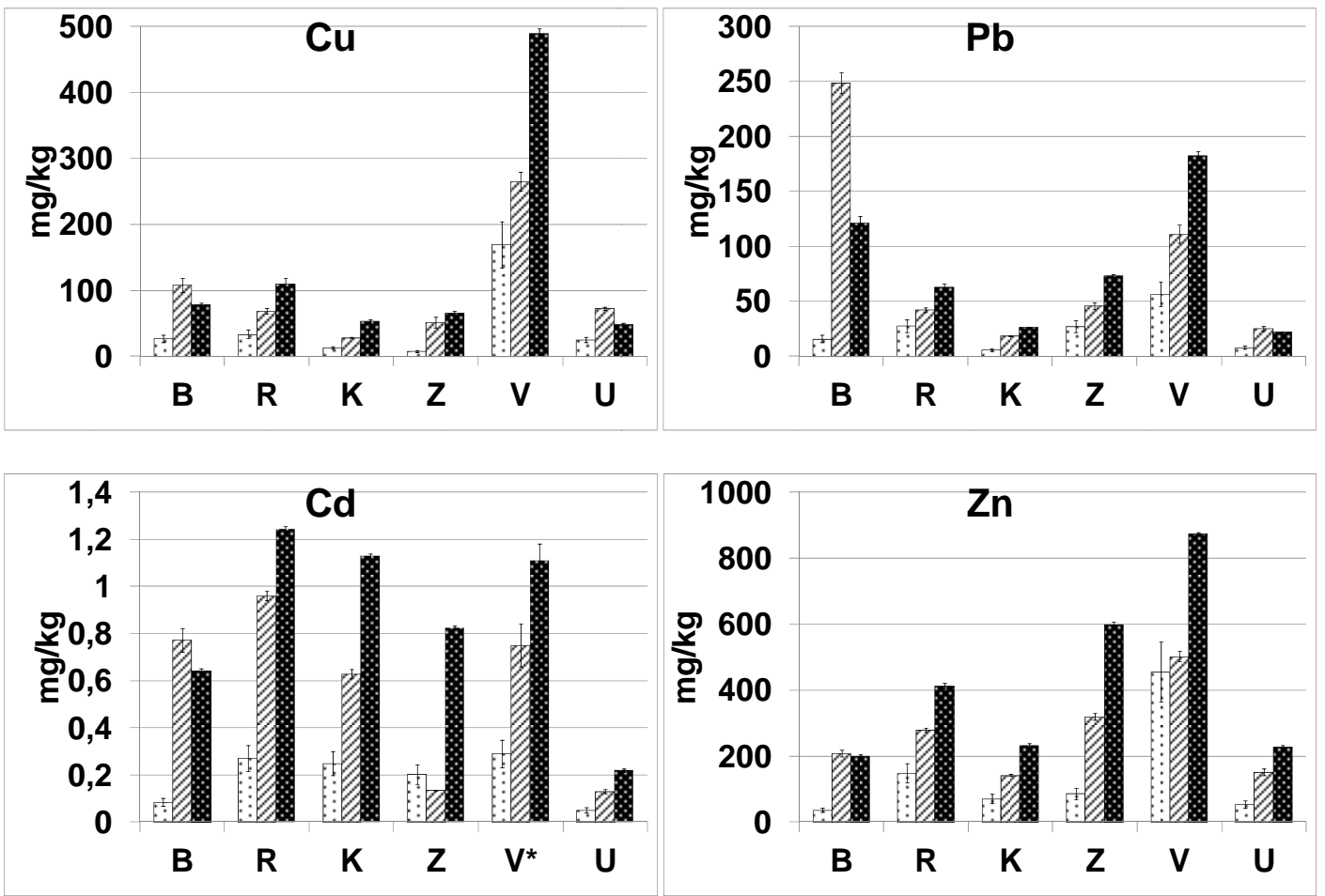

$\square>200 \square 63-200 \square<63$

Fig. (2). Concentrations of TMs in particular grain size fractions of sediment samples from the Botic creek (B), the Zatissky creek (Z) and the Vinorsky creek $(\mathrm{V}) .\left({ }^{*} \mathrm{Cd}\right.$ concentration for the Vinorsky creek is in this chart multiplied by 0.01$)$.
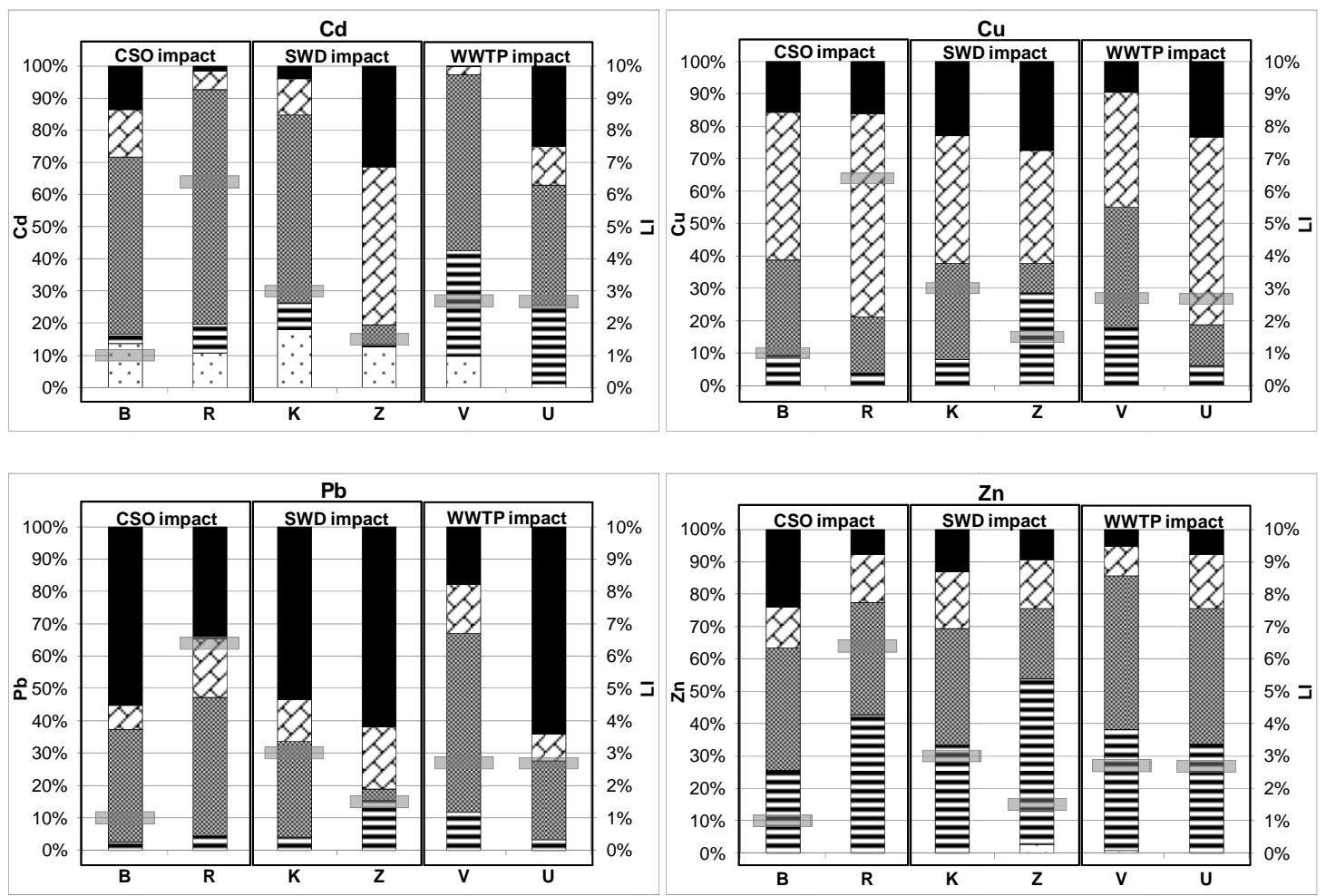

\section{๑exchangeable $\boxminus$ carbonates $\square \mathrm{Fe} / \mathrm{Mn}$ oxides $\otimes \mathrm{OM}$-residual $-\mathrm{LI}$}

Fig. (3). Metal distributions (\%) in particular sediment geochemical fractions selected for studying binding behaviour in sediments (1exchangeable fraction, 2-carbonates, 3-Fe/Mn oxides, 4- organic matter, 5-residual fraction). RSD of analyses up to $30 \%$. 
impacts as well as among the streams for particular metals. There was a higher bioavailability of $\mathrm{Cu}$ and $\mathrm{Zn}$ in the $\mathrm{Za}$ tissky creek impacted by SWD (the highest proportion bound to the two most available fractions) than in the creeks impacted by CSO, but this was not seen in the second creek impacted by SWD (the Kunraticky creek). Many factors affect the binding behavior and bioavailability of pollutants in sediment, including not only the type of main impact (CSO, SWD or WWTP) but also characteristics of the sediment material (OM and grain size distribution), the frequency of critical events as well as the level of contamination from other pollutants.

\section{CONCLUSIONS}

Despite the fact that trace metals prefer binding to solid phases in the aquatic environment, and should therefore be inactive and have relatively insignificant effects on aquatic organisms, this study shows that their release from sediments to water is a real possibility, reflecting a threat of toxic impacts on biota. The hazard assessment and study of binding behavior of TMs in sediment resulted in the following main conclusions:

- $\quad \mathrm{Cd}$ is the most available of the metals studied, but $\mathrm{K}_{\mathrm{d}}$ values imply that others may also be easily released from the sediment to liquid phase.

- Creeks with differing main impact showed different pollutant bioavailabilities from sediments. Some metals are more available in creeks impacted by WWTP $(\mathrm{Cu}$ and $\mathrm{Pb})$, others in the stream impacted by SWD ( $\mathrm{Zn}$ or $\mathrm{Pb}$ ); a decrease in $\mathrm{pH}$ during storm events may be one possible reason. On the other hand, pollutants in streams impacted by CSO seem to be less available (strong binding to AVS).

- More significant bioaccumulation of metals by benthic organisms confirms increased availability in the stream impacted by SWD.

- In some cases, such as in the creek impacted by CSO, metals do not necessarily bind preferentially to the finest sediment fraction.

This study shows that trace metals are still a very important problem in small urban streams, where sediments serve as storage sites. TMs can be released occasionally and uncontrolled from the sediment to water, and can cause significant and irreversible damage to aquatic ecosystems. Therefore, it is necessary to initiate measures in both urban drainages and in catchments to limit the inputs of these pollutants.

\section{CONFLICT OF INTEREST}

The authors confirm that this article content has no conflicts of interest.

\section{ACKNOWLEDGEMENTS}

This works was supported by the Czech Science Foundation project No. 203/08/P387, by the project of Ministry of Education of CR No. MSM 6840770002, the TACR project No. TA02020169 and projects n. SGS12/131/OHK1/2T/11 and SGS11/039/OHK1/1T/11.

\section{REFERENCES}

[1] Chambers PA, Allard M, Walker SL, et al. Impact of municipal wastewater effluents on Canadien waters: a review. Water Qual Res J Canada 1997; 32: 659-713.

[2] Marsalek J, Diamond M, Kok SK, Watt WE. Threats to sources of drinking water and aquatic ecosystem health in Canada: Urban runoff. NWRI Scientific Assess Rep Ser 2001; 1:47-50.

[3] Hatch AC, Burton GA. Sediment toxicity and stormwater runoff in a contaminated receiving system: consideration of different bioassays in the laboratory and field. Chemosphere 1999; 39: 1001-17.

[4] Burton Jr GA, Pitt R, Clark S. The role of traditional and novel toxicity test methods in assessing stormwater and sediment contamination. Crit Rev Environ Sci Tech 2002; 30: 413-47.

[5] Walsh CJ. Urban impacts on the ecology of receiving waters: a framework for assessment, conservation and restoration. Hydrobiologia 2000; 431: 635-551.

[6] Pitt R. Receiving water impacts associated with urban wet weather flows. In: Hoffman DJ, Rattner BA, Burton Jr GA, Cairns Jr J. Eds. Handbook of ecotoxicology, $2^{\text {nd }}$ ed: CRC/Lewis Publisher: Boca Raton, USA 2003; pp. 575-613.

[7] Grapentine L, Rochfort Q, Marsalek J. Benthic Responses to wetweather discharges in urban streams in southern Ontario. Water Qual Res J Canada 2004; 39: 374-91.

[8] Soares HMVM, Boaventura RAR, Machado AASC, Esteves Da Silva JCG. Sediments as monitors of heavy metal contamination in the Ave river basin (Portugal): multivariate analysis of data. Environ Pollut 1999; 105: 311-23.

[9] Nabelkova J. Heavy metals mobility in small urban creeks environment. Ph.D thesis CTU, Prague, Czech Rep 2005.

[10] Kominkova D. Pollution of Aquatic Ecosystems by Heavy Metals the Kocaba and the Tocnicky Stream. PhD. thesis. Charles University, Prague, Czech Rep 2001.

[11] Dauvalter V, Rognerud S. Heavy metals pollution in sediments of the Pasvik River drainage. Chemosphere 2001; 42: 9-18.

[12] Camusso M, Galassi S, Vignati D. Assessment of river Po sediment quality by micropollutant analysis. Water Res 2002; 36: 2491-504.

[13] Xia X, Wang R. Effect of sediment particle size on polycyclic aromatic hydrocarbon biodegradation: importance of the sedimentwater interface. Environ Toxicol Chem 2008; 27: 119-25.

[14] Tessier A, Campbell PGC, Bisson M. Sequential Extraction Procedure for the Speciation of Trace Metals. Anal Chem 1979; 51: 84451.

[15] Rauret G, Lopey-Sanchey JF, Sahuquillo A, Davidson C, Ure A, Quevauviller Ph. Improvement of the BCR three-step sequential extraction procedure prior to the certification of new sediment and soil reference material. J Environ Monit 1999; 1: 57-61

[16] Reid MK, Spencer KL, Shotbolt L. An appraisal of microwaveassisted Tessier and BCR sequential extraction method for the analysis of metals in sediment and soils. J Soils Sediments 2011; 11: 518-28

[17] Beltran R, de la Rosa JD, Santos JC, Beltran M, Gomez-Ariza JL. Heavy metals mobility assessment in sediments from the Odiel River (Iberian Pyritic Belt) using sequential extraction. Environ Earth Sci 2010; 61: 1493-503

[18] Oyeyiola AO, Olayinka O, Alo BI. Comparison of three sequential extraction protocols for the fractionation of potentially toxic metals in coastal sediments. Environ Monit Assess 2011; 172: 319-27

[19] Frankowski M, Ziola-Frankowska A, Kowalski A, Siepak J. Fractionation of heavy metals in bottom sediments using Tessier procedure. Environ Earth Sci 2010; 60: 1165-78

[20] Kominkova D. Impact of urban drainage on heavy metals bioaccumulation. Habilitation thesis. CTU. Prague, Czech Rep 2006.

[21] Government Order 229/2007 on the indicators and values of permissible pollution of surface water and wastewater, mandatory elements of the permits for discharge of wastewater into surface water and into sewerage systems, and on sensitive areas, Czech Rep. 2007.

[22] US EPA 402-R-99-004A. Understanding Variation in Partition Coefficient, Kd, Values. Volume I - Kd Model, Measurement Methods, and Application of Chemical Reaction Codes. Office of Air and Radiation, Washington DC: USA 1999.

[23] Barnthouse LW, DeAngelis DL, Gardner RH, Ońeill RV, Suter GV, Vaughan DS. Methodology for Environmental Risk Analysis. ORNL/TM-8167. Oak Ridge, TN 1982. 
[24] Clements WH, Carlisle DM, Lazorchak JM, Johnon PH. Heavy metals structure benthic communities in Colorado mountain streams. Ecol Appl 2000; 10 (2): 626-38.

[25] Kabala C, Singh BR. Fractionation and mobility of cooper, lead and zinc in soil profiles in the vicinity of a copper smelter. J Environ Qual 2001; 30: 485-92.

[26] Jain CK. Metal fractionation study on bed sediment of River Yamuna, India. Water Res 2004; 38: 569-78.

[27] Hnatukova P. Distribution of heavy metals in the environment of small urban streams. Ph.D. thesis, Charles University, Prague, Czech Rep 2007.

[28] Rand GM. Fundamentals of Aquatic Toxicology: Effects, Environmental Fate and Risk Assessment. $2^{\text {nd }}$ ed. North Palm Brach: Taylors \& Francis. 1995.
[29] John J, Salbu B, Gjessing ET, Bjornstad E. Effect of pH, humus concentration and molecular weight on conditional stability constants of cadmium. Water Res 1988; 22: 1381-8.

[30] Stumm W, Morgan JJ. Aquatic Chemistry, New York 1996.

[31] Allen HE, Fu G, Deng B. Analysis of Acid- Volatile Sulphide (AVS) and Simultaneously Extracted Metals (SEM) for the Estimation of Potential Toxicity in Aquatic Sediments. Environ Toxicol Chem 1993; 12(8): 1441- 53.

[32] Hansen DJ, Berry WJ, Mahony JD, et al. Predicting the Toxicity of Metal-Contaminated Field Sediments Using Interstitial Concentration of Metals and Acid-Volatile Sulfide Normalizations. Environ Toxicol Chem 1996; 15 (12): 2080 -94.

[33] Hoehn E, Gunten HR. Distribution of metal pollution in groundwater determided from sump sludges in wells. Water Sci Technol $1985 ; 17: 115-32$.

Received: October 15, 2012

Revised: November 11, 2012

Accepted: November 25, 2012

(C) Nabelkova and Kominkova: Licensee Bentham Open.

This is an open access article licensed under the terms of the Creative Commons Attribution Non-Commercial License (http://creativecommons.org/licenses/ by-nc/3.0/) which permits unrestricted, non-commercial use, distribution and reproduction in any medium, provided the work is properly cited. 